\title{
Using Apriori Algorithm to Determine Investigation Templates Specific to Intensive Care Units
}

\author{
Meryem Goral Yildizli (Corresponding author) \\ Cukurova University Faculty of Medicine Department of Biostatistics, Adana, Turkey \\ E-mail: meryem@cu.edu.tr \\ Zeliha Nazan Alparslan \\ Cukurova University Faculty of Medicine Department of Biostatistics, Adana, Turkey \\ E-mail: nazan@cu.edu.tr
}

\begin{abstract}
Objective: The development of new technologies, the improvements in the quality of health care provision and competition among health institutions are constantly increasing the expenditures in the field of health. It has become compulsory for health institutions, with their existing financial resources, to take serious measures to meet this increasing spending in order to sustain their existence. The aim of this study is to propose test templates suitable for the patient's profile in intensive units, to help physicians in diagnosis and treatment. This will help increasing service speed as well as quality and also reducing the laboratory expenditures, an important component of health expenditures.
\end{abstract}

Method: Laboratory test results, which health institutions refer to for diagnosis, are an intense and important data source of hospital information management systems. These data, when analyzed by data mining methods, can provide information to support healthcare professionals in their decisions and help the effective management of the health institutions. For this study, a data set containing examinations during the diagnosis/treatment processes and the demographic information of patients hospitalized in intensive care units in the year 2018 was created. The data set was initially analyzed with the Apriori Algorithm included in the open source WEKA program. Afterwards, laboratory tests and their rules of association suggested by the Apriori algorithm were determined. Laboratory test templates were then shaped according to the common characteristics of the medical and demographic information of the patients.

Results: First of all, data including 63686 records laboratory examinations of patients hospitalized in intensive care in 2018 were prepared. Using the Apriori Algorithm, the laboratory tests for which the confidence value was greater than or equal to 0.95 and the lift values indicating the importance of the rule were large were determined. From these tests, 17 rules that match the conditions of coexistence were formed, and a new data set containing 15785 records providing the rules was created. Templates specific to intensive care units were then created according to the results of the K-mean clustering algorithm applied on the data set.

Conclusion: Decision support systems, which are designed to help physicians to make more effective and correct decisions in their health care services are a part of hospital information management systems. Test templates that can be a module for these systems are defined in this study. Providing physicians with an intensive care unit specific template determined according to the patient's department and demographic characteristics will support the effective health service delivery. These templates will at the same time support the demand for rational orders be made by clinicians. This overall can reduce the laboratory test and treatment costs.

Keywords: Apriori algorithm, intensive care units, laboratory tests, templates

\section{Special Issue of Health Sciences}

DOI: $10.7176 / \mathrm{JSTR} / 6-03-08$

55 | P a g e

www.iiste.org 


\title{
Yoğun Bakım Birimlerine Özgü Tetkik Şablonların Belirlenmesi İçin Apriori Algoritma Kullanımı
}

\begin{abstract}
Özet
Amaç: Sağlık alanındaki teknolojilerin gelişimi, hizmet sunumunda kalitenin iyileştirilmesi ve sağlık kurumları arasındaki rekabetin büyümesiyle sağlık alanındaki harcamalar hızla artış göstermektedir. Sağlık kurumlarının mevcut finans kaynakları ile artan harcamaları karşılayıp varlıklarını sürdürebilmeleri için ciddi önlemler alması zorunlu hale gelmiştir. Çalışmanın amacı, hekimlerin tanı/tedavi hizmeti sunumlarına yardımcı olabilecek hastanın profiline uygun istem şablonları önermektir. Böylelikle hem hizmet kalitesi ve hızı arttırılıp, hem de sağlık harcamalarının önemli bileşeni olan laboratuvar tetkik harcamaları azaltılabilir.

Yöntem: Sağlık kurumları hastalık tanılarını belirlemede referans aldıkları laboratuvar test sonuçları hastane bilgi yönetim sistemlerinin yoğun ve önemli veri kaynağıdır. Veri madenciliği yöntemleri ile analiz edilen bu veriler, sağlık personelinin tıbbi kararlarında ve kurum yöneticilerinin kurumlarını efektif yönetmesine destek sağlayacak bilgiler sunulabilir. Bu amaçla, 2018 yılında yoğun bakım biriminde yatan hastaların demografik bilgileri ve tedavi sürecindeki tetkikleri içeren veri seti oluşturuldu. Veri seti açık kaynak kodlu WEKA programının içerdiği Apriori algoritması ile analiz edildi. Daha sonra Apriori algoritmasının öne çıkardığı birliktelik kurallarını içeren testler belirlendi, laboratuvar test şablonları bu tetkiklerin yapıldığı hastaların tedavi sürecindeki tıbbi, demografik bilgilerinin ortak özelliklerine göre şekillendirildi.

Bulgular: Öncelikle 2018 yılında yoğun bakımda yatan hastalara yapılan 63686 kaydı içeren laboratuvar tetkik verileri düzenlendi. Apriori Algoritması sonuçlarına göre güven değerinin 0.95 'den büyük/eșit olan kurallar kaldıraç değerlerine göre büyükten küçüğe doğru sıralanarak ilk 17 kural belirlendi. Değişkenlerin istatistiksel olarak bağımsız olduğu durumda kaldıraç (lift) değeri değişkenlerin beraber görünme ölçütünü ve kuralın önemini gösterir. Bu kuralları sağlayan 15785 kayıt içeren yeni veri seti düzenlendi. Bu veri seti üzerine uygulanan K-ortalama kümeleme algoritması sonuçlarına göre yoğun bakım birimlerine özgü şablonlar oluşturuldu.

Sonuç: Hekimlere sağlık hizmetleri sunumlarında daha etkili ve doğru karar vermelerine yardımcı olmak için tasarlanan karar destek sistemleri, hastane bilgi yönetim sistemlerinin bir parçası olarak kullanılmaktadır. Çalışmada bu sistemlerin bir modülü olabilecek istem şablonları tanımlanmıştır. Yoğun bakım hastalarına yapılan laboratuvar testlerinin hastanın yattı̆̆ birimi ve demografik özelliklerine göre belirlenen örüntülerin şablon olarak hekimlere sağlanması efektif sağlık hizmeti sunumuna destek olacaktır. Aynı zamanda belirlenen tetkik istem şablonlarının yoğun bakımların özellikleri açısından ilişkisi klinisyenler tarafindan yorumlanarak akılcıl istemlerin yapılması laboratuvar tetkiklerin maliyetini düşürerek tedavi masraflarını azaltabilir.
\end{abstract}

Anahtar Kelimeler: Apriori, yoğun bakım, laboratuvar tetkik, şabon

\section{Giriş}

Sağlık alanındaki teknolojilerin gelişimi, hizmet sunumunda kalitenin iyileştirilmesi ve sağlık kurumları arasındaki rekabetin çoğalmasıyla sağlık alanındaki harcamalar hızla artış göstermektedir.[1] , Global sağlık hizmeti harcamalarının 2013-2017 döneminde \% 2,9 olmasına karşın 2018-2022 döneminde yıllık \% 5,4 olarak çok fazla artış göstereceği öngörülmektedir.[2] Sağlık kurumlarının yönetiminde, çıktıların kalitesinden ödün vermeden girdileri ekonomik şekilde sağlayarak en fazla çıktı oluşturulmalıdır. Çünkü sağlık alanına ayrılmış sınırlı kaynaklarla sağlık hizmetlerinin kaliteli ve düşük maliyetli sunulması zorunludur.[1] Sağlık çalışanlarının performansı ve verimliliği, hastanelerin başarısını etkileyen en önemli faktörlerdendir. Sağllk hizmet sunumunun kalitesini belirlemede hekimlerin performansı belirleyicidir. Hekimlerin bilgi, beceri ve deneyimlerinin yanında hizmet sunumlarında onlara yardımcı olacak Karar Destek Sistemleri (KDS) gibi akıllı sistemlerin sağlanması performanslarını artıracaktır. Aynı zamanda bu sistemler Hastane Bilgi Yönetim Sistemlerinin (HBYS) içerdiği hastaların tıbbi ve demografik verilerinin kullanarak ortaya çıkardıkları örüntülerle gerek sağlık kurumu yöneticilerine gerekse hekimlerin tanı koyma ve tedavi planlaması sürecinde hastaların klinik bilgilerini dikkate alarak karar verebilmelerinde yol gösterici bilgiler sunarak hizmetlerinin efektif olmalarını sağlayabilir. Aynı zamanda bu sistemleri kullanarak yapılan akılcıl tetkik istemleri hastaların tedavisinde konforu artırırken sağlık harcamalarının önemli bileşeni olan laboratuvar tetkik harcamalarını azaltabilir.

56 | P a g e

www.iiste.org 


\section{Literatür Taraması}

Girgin ve arkadaşlarının [3] yaptığı çalışmada; özellikle bir haftadan uzun süre yoğun bakım ünitelerinde tedavi edilen kritik hastalarda laboratuvar incelemeleri için kan alınmasının transfüzyon gereksiniminde artış sağlamasına hastaların yatış sürelerinin ve hastalıkların kritikliği etkili olduğu belirtilmiş̧ir. Ayrıca gereksiz laboratuar incelemeleri ve hastalardan alınan kan alımı öncesi ve sonrasında kan ile temas eden sağlık personeline bulaşma riski, gereksiz tıbbi atıkların oluşması çevreye de zarar verdiği vurgulanmıştır.

Cismondi and at all.[4]çalışmalarında; gelecekte önerilecek laboratuar testlerinin faydasını tahmin etmek için yapay zeka yöntemi gastrointestinal kanaması olan 746 hastayı içeren yoğun bakım ünitesi veritabanındaki veriler üzerinde uygulanarak oluşturulan öngörücü modellerin gelecekteki laboratuar testlerinden elde edilebilecek bilgilerin yüksek doğrulukla tahmin edildiği vurgulanmıştır.

Pala and at all.[5] çalışmalarında; 286 hasta bilgilerini içeren meme kanseri veri seti üzerinde birliktelik kuralları öğrenme algoritmasına dayanan apriori algoritması çalıştırılmıştır. Oluşturulan kurallar, en güçlü veya en sık görülen, tekrarlayan meme kanserlerini içeren 10 kural listelenmiştir. Çalışmanın hekimlerin ve pratisyenlerin hastalıkların yorumlanmasında yardımcı olacağ 1 ve yaklaşımın diğer hastalıklar için kural türetmek için de kullanılabileceği belirtilmiş̧ir.

Kumar and Arumugaperumal.[6]; Birliktelik kuralları algoritmalarını kullanıldığı sağlık alanında yapılan araştırmaları özetleyen çalışmalarında vurgulanan bazı sonuçlar aşağıdaki gibi sıralanabilir. Ordonez ve arkadaşlarının kalp hastalığının olmamasının tahmin edildiği araştırmalarında, birliktelik algoritmasını çok boyutlu tıbbi veri setinde uygulayıp, öne çıkan birliktelik kuralları belirlemişlerdir. Laxminarayan ve arkadaşlarının yaptığı çalışmada hem statik hem de zamana bağlı özelliklerle açıklanan karmaşık veri setleri ile kişilerin klinik bilgileri ve uykudaki polisomno grafik kayıtları hem istatistiksel hem de ve klinik olarak olarak anlamlı ilişkileri ortaya çıkarmak için apriori algoritması kullanılmıştır. Shantakumar ve arkadaşlarının yaptığı çalışmada; kalp hastalıkların verilerini içeren veri tabanından K-ortalama algoritması kalp krizi veri setine uygulanarak oluşturulan kümeler daha sonra MAFIA (Maximum Frequent Itemset Algorithm) birliktelik algoritması ile kalp krizi tahmini için önemli olan desenler belirlenmiştir.

Rao and Devi. [7] çalışmalarında, Veri madenciliği teknikleri çok hızlı artan tıbbi kayıtların analizleri yapılarak araştırmacılara bilgilerin sunulmasındaki önem vurgulanmıştır. Ayrıca sağlık veri seti üzerinde yapılan çalışmada kalp hastalığı semptomları ile ilgili sağlık parametreleri arasındaki ilişkileri göstermede apriori algoritması sonuçları başarılı bulunmuştur.

Doddi and at all .[8] Büyük veri tabanının içerdiği tıbbi kayıt verileriyle, hastaların tedavisinde uygulanan işlemler ile hastalara ait teşhisler arasındaki ilişkilendirme kurallarını Apriori algoritması ile belirlenmiştir. Belirli bir tanı için yaygın olarak uygulanan işlemler setinin belirlenmesi tedavi sürecine fayda sağlayacağı vurgulanmıştır.

\section{Birliktelik Kuralları}

Birliktelik kuralları; büyük veri setlerindeki değişkenler arasındaki korelasyon, ilişki ve birliktelik olasılığı gibi farklı istatistik ölçü değerlerine göre oransal ilişki kurarak öne çıkan kuralları belirleyen algoritmalardan oluşturulur. Algoritmalar olabilecek bütün örüntüleri ortaya çıkarması, kullanışlıllı̆̆ ve kolay anlaşılabilirliği olması yöntemin kullanılmasını artmaktadır.[9]

Birliktelik Kuralı Matematiksel olarak tanımı:

$\mathrm{I}=\{\mathrm{i} 1, \mathrm{i} 2, \ldots \mathrm{im}\}$ veri tabanındaki nesneler kümesi, $\mathrm{T}=\left\{\mathrm{t}_{1}, \mathrm{t}_{2}, \ldots \mathrm{t}_{\mathrm{n}}\right\}$ nesnelere ait işlemler kümesi, $\mathrm{T}$ $\subseteq \mathrm{I}, \mathrm{t}_{\mathrm{n}}=\mathrm{v}$ olmak üzere; $\mathrm{X} \subseteq \mathrm{I}, \mathrm{Y} \subseteq \mathrm{I}$ kümesine ait bir nesneler ve $\mathrm{X} \cap \mathrm{Y}=\varnothing$ ise, $\mathrm{X} \rightarrow \mathrm{Y}$ ilişkilendirme kuralı olarak belirtilir.[9]

Birliktelik kuralı içerisinde oluşan kuralın etkisinin ölçülmesine yardımcı olan destek (support), güven (confidence) ve kaldıraç (lift) olmak üzere üç temel parametre kullanılır.[10]

Destek Değeri: Veri içerisinde yer alan nesnelerin birbirleriyle olan ilişkilerinin sıklığını gösterir. $A \rightarrow B$ birliktelik kuralının destek değeri; A ve B nesnelerinin bütün veritabanında yüzde kaç ihtimalle bulunduğunu gösterir, hesaplanmasında eşitlik (1.1) kullanılır.

$$
\text { Destek } \mathrm{P}(\mathrm{A} \rightarrow \mathrm{B})=\frac{\mathrm{P}(\mathrm{A} \wedge \mathrm{B})}{\text { Toplam kaylt sayıs }}(A, B \text { veritabanina ait nesneler })
$$

Güven Değeri: A $\rightarrow$ B birliktelik kuralının güven değeri A'yı içeren kayıtların B'yide içerme yüzdesidir. Güven düzeyi, kuralın gücünü ifade eder, (1.2) deki eşitliğe göre hesaplanır. 


$$
\text { Güven } \mathrm{P}(\mathrm{A} \rightarrow \mathrm{B})=\frac{\mathrm{P}(\mathrm{A} \wedge \mathrm{B})}{\mathrm{P}(\mathrm{A})}(A, B \text { veritabanına ait nesneler })
$$

Kaldıraç Değeri: A ve B nesnelerinin istatistiksel olarak bağımsız olması halinde ne kadar birlikte geçtiklerini belirler, aynı zamanda kuralın performansını temsil eder. Bu değer 1 den büyükse iki olayın birbirleriyle ilişkili olduğunu ve kuralın gelecekdeki işlemlerde kullanılabilceği söylenebilir, (1.3) deki eşitlik kullanılır.

$$
\text { Kaldıraç } \mathrm{P}(\mathrm{A} \rightarrow \mathrm{B})=\frac{\text { Güven } \mathrm{P}(\mathrm{A} \rightarrow \mathrm{B})}{(\text { destek } \mathrm{B})}(A, B \text { veritabanına ait nesneler })
$$

\subsection{Apriori Algoritması}

Birliktelik kuralları çıkaran algoritmalardan yaygın olarak kullanılan Apriori algoritması Agrawal ve Srikant tarafından 1994 yılında geliştirilmiştir.[10]

Apriori Algoritmasinın Adımlar1;

1. Minimum destek sayısı (min.support), minimum güven değeri (min.confidence) belirlenir. (Değişkenlerin istatistiksel olarak bağımsız olması durumunda kaldıraç (lift) değeri değişkenlerin bir arada bulunma ölçütünü verir, değeri 1 den büyük olmalıdır.)

2. Öğe kümeler içerisindeki her bir öğenin destek değerleri bulunur.

3. Minimum destek değerinden daha düşük desteğe sahip öğeler kümeden çıkartılır.

4. Kalan tekli birliktelikler dikkate alınarak ikili birliktelikler oluşturulur.

5. Minimum destek değerinden daha düşük desteğe sahip öğeler kümeden çıkartılır.

6. Kalan ikili birliktelikler dikkate alınarak üçlü birliktelikler oluşturulur.

7. Minimum destek değerinden daha düşük desteğe sahip öğeler kümeden çıkartılır.

8. Bu döngü minimum destek değerinden daha büyük öğe kalmayana kadar devam eder.

9. Birliktelik kuralları çıkartılır.

\subsection{K-Ortalama Algoritması}

Kümeleme, büyük sayıda gruplanmamış verileri birbirlerine uzaklıkları/benzerliklerine göre verileri daha az boyuta indirerek kümelere ayırıp anlamlı bilgileri oluşturmaktır. K-Ortalama kümeleme algoritması kolay kullanımı ve büyük boyutlu verilere uygulanabilirliği nedeniyle sağlık alanındaki araştırmalarda yaygın olarak tercih edilmektedir.[11]

K-Ortalama Algoritmasının Aşamaları;

1. $\mathrm{k}$ tane küme merkezi rastgele seçilir.

2. Her verinin seçilen merkez noktalara olan uzaklığı/benzerliği hesaplanır.

3. Veri setindeki kayıtlar merkezlere olan uzaklıklarına göre en yakın merkezin kümesine atanır.

4. Oluşan kümelerin tüm elemanlarının ortalama değeri yeni küme merkezi olarak belirlenir.

5. Merkez noktalar değişmeyene kadar 2. ve 4. adımlar tekrarlanır.

\section{Yöntem ve Materyal}

Çukurova Üniversitesi Balcalı hastanesine 2018 y1lında beyin cerrahi, dahiliye, genel cerrahi, koroner bakım, reanimasyon,nöroloji, çocuk yenidoğan ve çocuk yoğun bakımda yatan hastalara yapılan 92 çeşit laborauvar tetkikini içeren 63686 istem kaydı hastane bilgi yönetim sistemindeki veri tabanından alınmıştır. Analiz sürecinin birinci aşamasında, hastalara yapılan tetkiklerden önemli olan birliktelik kuralını belirlemek amacıyla veri madenciliği Weka 3.9.3 Programı ile birliktelik kuralı yöntemlerinden apriori algoritması ile analiz edilerek 35 kural bulunmuştur. destek değeri \%10, güven değeri \%95 ve kaldıraç değeri 3 parametre değerleri ile analiz edilerek 35 kural bulunmuştur. Değişkenlerin istatistiksel olarak bağımsız olması halinde, ne kadar birlikte geçtiklerinin ölçütü olan kaldıraç (lift) değeri kullanılarak öne çıkan kurallar belirlendi. Oluşturulan kurallardan güven değeri \%95 ve üstü olanlar, kaldıraç değerlerine göre büyükden küçüğe doğru sıralanarak ilk 17 kural tespit edildi. Bu kuralların bulunduğu 19896 kayıtlık veri setinden çocuk yenidoğan ve çocuk yoğun bakım hastaları çıkartılarak ikinci aşama analizi için 15785 kayıt içeren veri seti düzenlenmiştir. İndirgenmiş veri setine hastanın yattığ1 yoğun bakım birimi, cinsiyet, yaş, yatış süresi değişken verileri eklenerek oluşturulan normalize edilmiş $(0,1$ aralığına) yeni veri seti üzerinde uygulanan K-ortalama kümeleme sonuçlarına göre yoğun bakım birimlerine uygun istem şablonları belirlenmiştir. Analiz süreci Şekil 1, veri seti yapıları Tablo1 ve Tablo 2'de gösterilmiştir. 


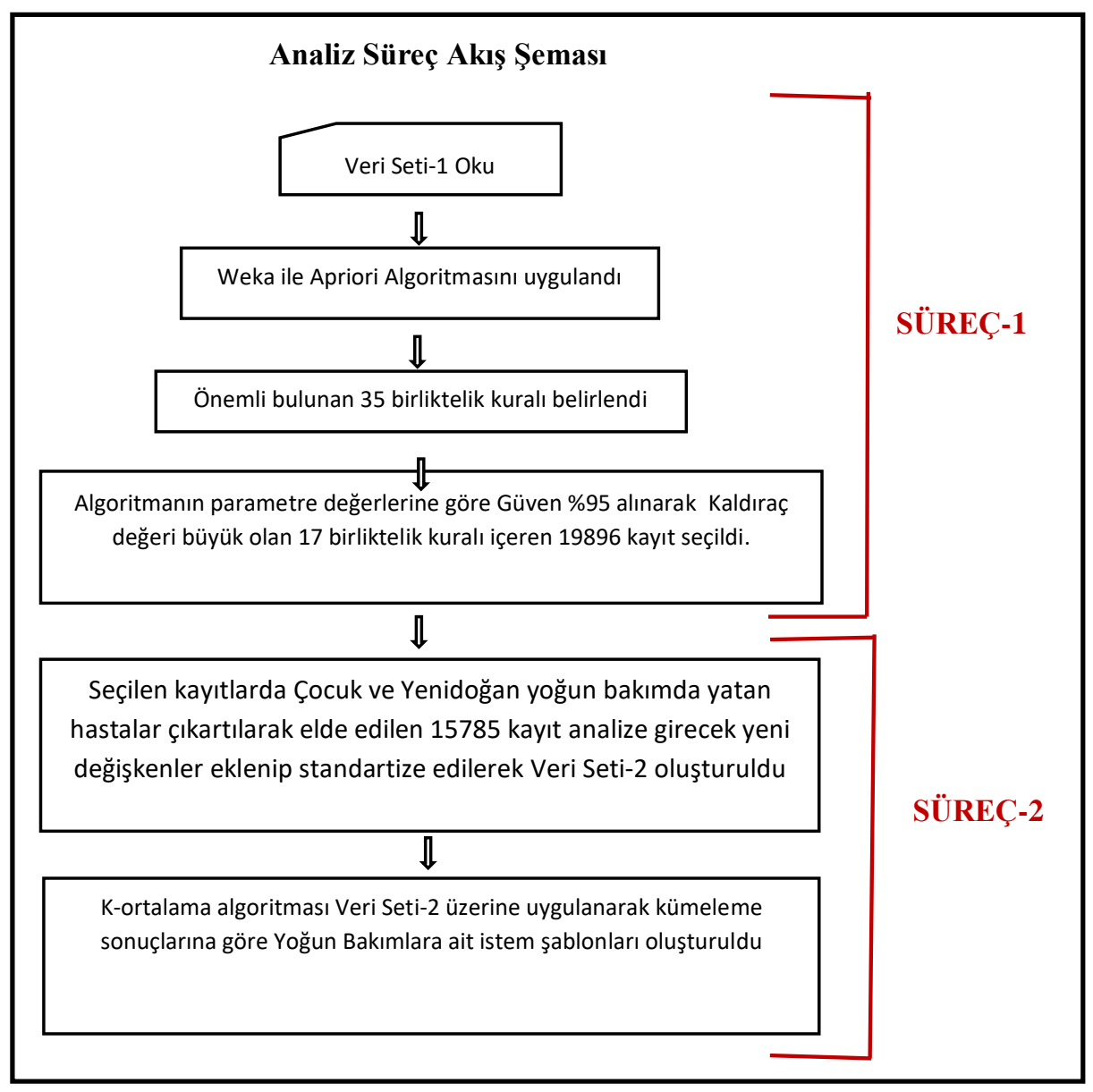

Şekil 1. Analiz Süreci

Tablo 1. Veri Seti Yapısı (Analiz Aşaması-1)

\begin{tabular}{|l|l|l|}
\hline \multicolumn{2}{|c|}{ 1. Aşama Veri Seti Yapısı } \\
\hline Değişken Adı & $\begin{array}{c}\text { Değişken } \\
\text { Tipi }\end{array}$ & \multicolumn{1}{c|}{ Açılama } \\
\hline İstemno & Sayısal & Hastanın diğer bilgileriyle ilişkilendirilen anahtar değişken \\
\hline Tekik Kod_1 & Sayısal & $($ Var : 1, Yok:0 ) İstemde olup olmadığını gösterir \\
\hline Tekik Kod_2 & Sayısal & (Var : 1, Yok:0 ) İstemde olup olmadığını gösterir \\
\hline$\ldots$ & & \\
\hline$\ldots$ & & \\
\hline$\ldots$ & & $($ Var : 1, Yok:0 ) İstemde olup olmadığını gösterir \\
\hline \multicolumn{2}{|l|}{ Tekik Kod_92 } & Sayısal \\
\hline \multicolumn{2}{|l}{ Analize Giren Tetkik Çeşidi : 92 Toplam Kayıt Sayısı : 63686 } \\
\hline
\end{tabular}


Tablo 2. Veri Seti Yapısı (Analiz Aşaması-2)

\begin{tabular}{|c|c|c|}
\hline \multicolumn{3}{|r|}{ 2. Aşama Veri Seti Yapısı } \\
\hline Değişken Adı & $\begin{array}{l}\text { Değişken } \\
\text { Tipi }\end{array}$ & Açıklama \\
\hline Birim Kod & Sayisal & Hastanın yattığı yoğun bakım (kodlanmış) \\
\hline Yaş & Sayısal & Hastanın yaşı \\
\hline Yatış Süresi & Sayısal & Yoğun bakımda yattığı süre \\
\hline Cinsiyet kod & Sayısal & Hastanın cinsiyeti (kodlanmış) \\
\hline İstemno & Sayısal & $\begin{array}{l}\text { Hastaya yapılan istemin numarası (tekiklerle diğer bilgileri } \\
\text { ilişkilendiren anahtar değişken) }\end{array}$ \\
\hline Tekik Kod_1 & Sayısal & (Var : 1, Yok:0 ) İstemde olup olmadığını gösterir \\
\hline Tekik Kod_2 & Sayısal & (Var: 1, Yok:0 ) İstemde olup olmadığını gösterir \\
\hline \multicolumn{3}{|l|}{$\ldots$} \\
\hline \multicolumn{3}{|l|}{$\ldots$} \\
\hline \multicolumn{3}{|l|}{$\ldots$} \\
\hline Tekik Kod 92 & Sayısal & (Var : 1, Yok:0 ) İstemde olup olmadığını gösterir \\
\hline \multicolumn{3}{|c|}{ Analize Giren Tetkik Çeşidi: $92 \quad$ Toplam Kayıt Sayısı: 15785} \\
\hline
\end{tabular}

\section{Bulgular}

İki aşamalı analiz sürecinin birinci aşamasında; Apriori algoritması sonuçlarına göre 35 kuraldan öne çıkan 17 birliktelik kuralı ve parametre değerleri Tablo 3, tetkik kod ve adları Tablo 4'te gösterilmiştir.

Tablo 3. Apriori Algoritması Kurallarından Öne Çıkan 17 Birliktelik Kuralı ve Tetkikleri

\begin{tabular}{|c|c|c|c|}
\hline \multicolumn{4}{|c|}{ Destek Değeri \%10, Güven Değeri > \%95, Kaldıraç Değeri > 3 Olan Kurallar (17 Kural) } \\
\hline $\begin{array}{c}\text { Apriori } \\
\text { Kural } \\
\text { No }\end{array}$ & Apriori Kural & $\begin{array}{c}\text { Güven } \\
\text { (Confidence) }\end{array}$ & $\begin{array}{c}\text { Kaldıraç } \\
\text { (Lift) }\end{array}$ \\
\hline 1 & $\mathrm{~T} 904290==>\mathrm{T} 905320$ & 0.99 & 4.14 \\
\hline 4 & T901940 T900580 T901260 ==> T902210 T900200 T902420 & 0.98 & 3.71 \\
\hline 6 & T902210 Т900580 T901260 ==> T901940 T900200 T902420 & 0.98 & 3.71 \\
\hline 7 & T902210 T900200 T901260 ==> T901940 T900580 T902420 & 0.98 & 3.71 \\
\hline 9 & T901940 T900200 T901260 ==> T902210 T900580 T902420 & 0.98 & 3.71 \\
\hline 12 & T900580 T901260 ==> T902210 T901940 T900200 T902420 & 0.98 & 3.7 \\
\hline 14 & T900200 T901260 ==> T902210 Т901940 Т900580 Т902420 & 0.98 & 3.7 \\
\hline 16 & T900580 Т901260 ==> T901940 Т900200 Т902420 & 0.98 & 3.7 \\
\hline 17 & T900580 T901260 ==> T902210 T900200 T902420 & 0.98 & 3.7 \\
\hline 20 & T900200 Т901260 ==> Т901940 Т900580 Т902420 & 0.98 & 3.7 \\
\hline 22 & T902210 T901940 T900580 T901260 ==> T900200 T902420 & 0.98 & 3.7 \\
\hline 24 & T901940 T900580 T901260 ==> T900200 T902420 & 0.98 & 3.7 \\
\hline 26 & T900200 T901260 ==> T902210 T900580 T902420 & 0.98 & 3.7 \\
\hline 28 & T902210 T900580 T901260 ==> T900200 T902420 & 0.98 & 3.7 \\
\hline 30 & T902210 T901940 T900200 T901260 ==> T900580 T902420 & 0.98 & 3.7 \\
\hline 32 & T901940 T900200 T901260 ==> T900580 T902420 & 0.98 & 3.7 \\
\hline 33 & T900580 T901260==> T900200 T902420 & 0.98 & 3.7 \\
\hline
\end{tabular}


Tablo 4. Apriori Algoritması Sonuçlarına Göre Önemli Kuralların Tetkikleri

\begin{tabular}{|l|l|}
\hline Tetkik Kod & Tetkiki Adı \\
\hline T900200 & ALANIN AMINOTRANSFERAZ (ALT) \\
\hline T900580 & ASPARTAT TRANSAMINAZ (AST) \\
\hline T901260 & FOSFOR (P) \\
\hline T901940 & KAN ÜRE AZOTU (BUN) \\
\hline T902210 & KREATININ \\
\hline T902420 & MAGNEZYUM \\
\hline T904290 & APTT \\
\hline T905320 & PROTROMBIN ZAMANI (KOAGÜLOMETRE) \\
\hline
\end{tabular}

Analiz sürecinin 1.aşamasından önemli bulununan kuralları içeren kayıtların veri setine hastanın yattığı yoğunbakım birimi, yaşı, yatış süresi, cinsiyet analiz değişkenleri eklenerek veri seti-2 oluşturuldu. Analiz değişkenlerinin yoğunbakım hastalarının tedavi sürecinde yapılan tetkiklere etkisini belirlemek amacıyla K-ortalama kümeleme algoritması uygulandı. Kümeleme sonuçlarına göre öncelikle birimlere özgü olabilecek beş çeşit istem grubu Tablo 5' verilmiştir.

Tablo 5. Apriori Algoritması Sonuçlarına Göre Olabilecek İstem Grupları

\begin{tabular}{|c|c|c|}
\hline $\begin{array}{c}\text { İstem Grup } \\
\text { Adı }\end{array}$ & Apriori Kural No & Tetkikler \\
\hline Grup 1 & 1 & $\begin{array}{l}\text { APTT } \\
\text { PROTROMBİN ZAMANI }\end{array}$ \\
\hline Grup 2 & $4,7,9,12,14,22,30$ & $\begin{array}{l}\text { ALANIN AMINOTRANSFERAZ } \\
\text { ASPARTAT TRANSAMINAZ } \\
\text { FOSFOR } \\
\text { KAN ÜRE AZOTU } \\
\text { KREATININ } \\
\text { MAGNEZYUM }\end{array}$ \\
\hline Grup 3 & $16,20,24,32$ & $\begin{array}{l}\text { ALANIN AMINOTRANSFERAZ } \\
\text { ASPARTAT TRANSAMINAZ } \\
\text { FOSFOR } \\
\text { KAN ÜRE AZOTU } \\
\text { MAGNEZYUM } \\
\end{array}$ \\
\hline Grup 4 & $17,26,28$ & $\begin{array}{l}\text { ALANIN AMINOTRANSFERAZ } \\
\text { ASPARTAT TRANSAMINAZ } \\
\text { FOSFOR } \\
\text { KREATININ MAGNEZYUM } \\
\text { MAGNEZYUM } \\
\end{array}$ \\
\hline Grup 5 & 33 & $\begin{array}{l}\text { ALANIN AMINOTRANSFERAZ } \\
\text { ASPARTAT TRANSAMINAZ } \\
\text { FOSFOR } \\
\text { MAGNEZYUM }\end{array}$ \\
\hline
\end{tabular}

Yoğun bakımların tetkik kullanım yüzdeleri (\%3 den büyük) ve analiz değişkenlerine göre dağılımlar

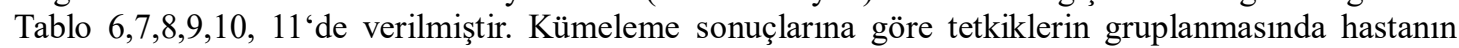
yattığ1 yoğun bakım birimi etkili olmasına karşın cinsiyet, yaş ve yatış süreleri etkili olmamıştır. Birimlere özgü şablonları belirlemede ise yoğun bakım ve tedavi sürecinde yapılan tetkikler belirleyici olmuştur. 
International Journal of Scientific and Technological Research

ISSN 2422-8702 (Online), DOI: 10.7176/JSTR/6-03-08

Special Issue of Health Sciences, Vol.6, No.3, 2020

Tablo 6. Beyin Cerrahi Yoğun Bakım İstemlerinin Tetkik Grupları ve Analiz Değişkenlerine Dağı̆lımı

\begin{tabular}{|c|c|c|c|c|c|c|c|c|c|}
\hline \multirow{2}{*}{$\begin{array}{l}\text { Yoğun } \\
\text { Bakım }\end{array}$} & \multirow{2}{*}{$\begin{array}{c}\text { Tetkik } \\
\text { Yüzdesi (\%3 } \\
\text { ve üstü) }\end{array}$} & \multirow[t]{2}{*}{ Cinsiyet } & \multicolumn{5}{|c|}{$\begin{array}{l}\text { İstem } \\
\text { Grupları }\end{array}$} & \multirow{2}{*}{$\begin{array}{c}\text { Ortalama } \\
\text { Yatış } \\
\text { Süresi }\end{array}$} & \multirow{2}{*}{$\begin{array}{c}\text { Ortalama } \\
\text { Yaş }\end{array}$} \\
\hline & & & 1 & 2 & 3 & 4 & 5 & & \\
\hline \multirow{6}{*}{$\begin{array}{l}\text { Beyin } \\
\text { Cerrahi }\end{array}$} & 44.14 & $\mathrm{E}$ & $X$ & & & & & 16.58 & 47.29 \\
\hline & 28.54 & K & $\mathrm{X}$ & & & & & 13.54 & 47.99 \\
\hline & 7.84 & $\mathrm{E}$ & & $\mathrm{X}$ & $X$ & $\mathrm{X}$ & $\mathrm{X}$ & 24.23 & 40.86 \\
\hline & 7.28 & $\mathrm{~K}$ & & $\mathrm{X}$ & $\mathrm{X}$ & $\mathrm{X}$ & $\mathrm{X}$ & 24.73 & 44.94 \\
\hline & 6.62 & $\mathrm{E}$ & $\mathrm{X}$ & $\mathrm{X}$ & X & $\mathrm{X}$ & X & 16.83 & 45.44 \\
\hline & 5.2 & K & $\mathrm{X}$ & $X$ & $X$ & $X$ & $X$ & 23.33 & 51.6 \\
\hline
\end{tabular}

Tablo 7. Dahiliye Yoğun Bakım İstemlerinin Tetkik Grupları ve Analiz Değişkenlerine Dağılımı

\begin{tabular}{|c|c|c|c|c|c|c|c|c|c|}
\hline \multirow{2}{*}{$\begin{array}{l}\text { Yoğun } \\
\text { Bakım }\end{array}$} & \multirow{2}{*}{$\begin{array}{c}\text { Tetkik } \\
\text { Yüzdesi } \\
\text { (\%3 ve üstü) }\end{array}$} & \multirow{2}{*}{ Cinsiyet } & \multicolumn{5}{|c|}{$\begin{array}{l}\text { İstem } \\
\text { Grupları }\end{array}$} & \multirow{2}{*}{$\begin{array}{c}\text { Ortalama } \\
\text { Yatış } \\
\text { Süresi }\end{array}$} & \multirow{2}{*}{$\begin{array}{c}\text { Ortalama } \\
\text { Yaş }\end{array}$} \\
\hline & & & 1 & 2 & 3 & 4 & 5 & & \\
\hline \multirow{6}{*}{ Dahiliye } & 39.97 & E & $X$ & $X$ & $\mathrm{X}$ & $X$ & $X$ & 14.52 & 60.69 \\
\hline & 35.97 & K & $\mathrm{X}$ & $X$ & $X$ & $\mathrm{X}$ & $X$ & 16.8 & 65.68 \\
\hline & 9.26 & E & $X$ & & & & & 12.04 & 60.12 \\
\hline & 6.41 & K & $\mathrm{X}$ & & & & & 14.5 & 59.1 \\
\hline & 4.46 & $\mathrm{E}$ & & $\mathrm{X}$ & $X$ & $\mathrm{X}$ & $X$ & 14.11 & 62.29 \\
\hline & 3.5 & K & & $X$ & $X$ & $X$ & $X$ & 15.01 & 64.46 \\
\hline
\end{tabular}

Tablo 8. Genel Cerrahi Yoğun Bakım İstemlerinin Tetkik Grupları ve Analiz Değişkenlerine Dağılımı

\begin{tabular}{|c|c|c|c|c|c|c|c|c|c|}
\hline \multirow{2}{*}{$\begin{array}{l}\text { Yoğun } \\
\text { Bakım }\end{array}$} & \multirow{2}{*}{$\begin{array}{c}\text { Tetkik } \\
\text { Yüzdesi } \\
\text { (\%3 ve üstii) }\end{array}$} & \multirow{2}{*}{ Cinsiyet } & \multicolumn{5}{|c|}{$\begin{array}{c}\text { İstem } \\
\text { Grupları }\end{array}$} & \multirow{2}{*}{$\begin{array}{c}\text { Ortalama } \\
\text { Yatış } \\
\text { Süresi }\end{array}$} & \multirow{2}{*}{$\begin{array}{c}\text { Ortalama } \\
\text { Yaş }\end{array}$} \\
\hline & & & 1 & 2 & 3 & 4 & 5 & & \\
\hline \multirow{4}{*}{$\begin{array}{l}\text { Genel } \\
\text { Cerrahi }\end{array}$} & 54.49 & E & X & & & & & 18.43 & 58.13 \\
\hline & 33.72 & K & X & & & & & 13.86 & 63.32 \\
\hline & 4.78 & $\mathrm{~K}$ & & $\mathrm{X}$ & $X$ & $X$ & $X$ & 16.69 & 60.42 \\
\hline & 4.12 & $\mathrm{E}$ & & $X$ & $\mathrm{X}$ & $\mathrm{X}$ & $X$ & 15.24 & 60.34 \\
\hline
\end{tabular}


Special Issue of Health Sciences, Vol.6, No.3, 2020

Tablo 9. Koroner Yoğun Bakım İstemlerinin Tetkik Grupları ve Analiz Değişkenlerine Dağılımı

\begin{tabular}{|c|c|c|c|c|c|c|c|c|c|}
\hline \multirow{2}{*}{$\begin{array}{l}\text { Yoğun } \\
\text { Bakım }\end{array}$} & \multirow{2}{*}{$\begin{array}{l}\text { Tetkik } \\
\text { Yüzdesi } \\
\text { (\%3 ve } \\
\text { üstï) }\end{array}$} & \multirow{2}{*}{ Cinsiyet } & \multicolumn{5}{|c|}{$\begin{array}{l}\text { İstem } \\
\text { Grupları }\end{array}$} & \multirow{2}{*}{$\begin{array}{c}\text { Ortalama } \\
\text { Yatış } \\
\text { Süresi }\end{array}$} & \multirow{2}{*}{$\begin{array}{c}\text { Ortalama } \\
\text { Yaş }\end{array}$} \\
\hline & & & 1 & 2 & 3 & 4 & 5 & & \\
\hline \multirow{6}{*}{ Koroner } & 24.95 & E & $\mathrm{X}$ & & & & & 4.14 & 62.43 \\
\hline & 19.67 & K & $\mathrm{X}$ & & & & & 3.93 & 63.48 \\
\hline & 15.31 & E & $\mathrm{X}$ & $X$ & $X$ & $\mathrm{X}$ & $\mathrm{X}$ & 3.4 & 62.55 \\
\hline & 14.79 & $\mathrm{E}$ & & $X$ & $\mathrm{X}$ & $\mathrm{X}$ & $\mathrm{X}$ & 4.68 & 64.22 \\
\hline & 12.94 & K & & $X$ & $\mathrm{X}$ & $\mathrm{X}$ & $\mathrm{X}$ & 4.62 & 68.99 \\
\hline & 11.75 & $\mathrm{~K}$ & $X$ & $\mathrm{X}$ & $\mathrm{X}$ & $\mathrm{X}$ & $\mathrm{X}$ & 3.34 & 66.98 \\
\hline
\end{tabular}

Tablo 10. Nöroloji Yoğun Bakım İstemlerinin Tetkik Grupları ve Analiz Değişkenlerine Dağılımı

\begin{tabular}{|c|c|c|c|c|c|c|c|c|c|}
\hline \multirow{2}{*}{$\begin{array}{l}\text { Yoğun } \\
\text { Bakım }\end{array}$} & \multirow{2}{*}{$\begin{array}{c}\text { Tetkik } \\
\text { Yüzdesi } \\
\text { (\%3 ve üstü) }\end{array}$} & \multirow[t]{2}{*}{ Cinsiyet } & \multicolumn{5}{|c|}{$\begin{array}{l}\text { İstem } \\
\text { Grupları }\end{array}$} & \multirow{2}{*}{$\begin{array}{c}\text { Ortalama } \\
\text { Yatış } \\
\text { Süresi }\end{array}$} & \multirow{2}{*}{$\begin{array}{c}\text { Ortalama } \\
\text { Yaş }\end{array}$} \\
\hline & & & 1 & 2 & 3 & 4 & 5 & & \\
\hline \multirow{6}{*}{ Nöroloji } & 35.65 & $\mathrm{~K}$ & & X & $X$ & $\mathrm{X}$ & $X$ & 20.96 & 59.73 \\
\hline & 27.17 & $\mathrm{E}$ & & $X$ & $X$ & $\mathrm{X}$ & $X$ & 15.71 & 63.11 \\
\hline & 14.78 & K & $X$ & $X$ & $\mathrm{X}$ & $X$ & $X$ & 19.44 & 59.8 \\
\hline & 11.98 & E & $X$ & $X$ & $X$ & $X$ & $X$ & 14.37 & 63.53 \\
\hline & 5.24 & $\mathrm{E}$ & $\mathrm{X}$ & & & & & 15.29 & 60.08 \\
\hline & 4.8 & K & X & & & & & 17.41 & 59.67 \\
\hline
\end{tabular}

Tablo 11. Reanimasyon Yoğun Bakım İstemlerinin Tetkik Grupları ve Analiz Değişkenlerine Dağılımı

\begin{tabular}{|c|c|c|c|c|c|c|c|c|c|}
\hline \multirow{2}{*}{$\begin{array}{l}\text { Yoğun } \\
\text { Bakım }\end{array}$} & \multirow{2}{*}{$\begin{array}{c}\text { Tetkik } \\
\text { Yüzdesi } \\
\text { (\%3 ve üstü) }\end{array}$} & \multirow[t]{2}{*}{ Cinsiyet } & \multicolumn{5}{|c|}{$\begin{array}{l}\text { İstem } \\
\text { Grupları }\end{array}$} & \multirow{2}{*}{$\begin{array}{c}\text { Ortalama } \\
\text { Yatış } \\
\text { Süresi }\end{array}$} & \multirow{2}{*}{$\begin{array}{c}\text { Ortalama } \\
\text { Yaş }\end{array}$} \\
\hline & & & 1 & 2 & 3 & 4 & 5 & & \\
\hline \multirow{6}{*}{ Reanimasyon } & 21.27 & E & $\mathrm{X}$ & $\mathrm{X}$ & $\mathrm{X}$ & $\mathrm{X}$ & $X$ & 17.98 & 50.21 \\
\hline & 20.98 & $\mathrm{E}$ & & $\mathrm{X}$ & $X$ & $\mathrm{X}$ & $X$ & 24.91 & 46.64 \\
\hline & 20.84 & K & $\mathrm{X}$ & $\mathrm{X}$ & $\mathrm{X}$ & $\mathrm{X}$ & $\mathrm{X}$ & 20.95 & 57.42 \\
\hline & 17.68 & K & & $\mathrm{X}$ & $\bar{X}$ & $\mathrm{X}$ & $X$ & 23.4 & 56.77 \\
\hline & 10.29 & E & $X$ & & & & & 17.94 & 49.97 \\
\hline & 8.64 & K & $\mathrm{X}$ & & & & & 19.79 & 58.02 \\
\hline
\end{tabular}

Yoğun bakımların tetkik istem yüzdelikleri incelendiğinde birimlere özgü 3 tipik şablon belirlenmiş, şablon içerikleri Tablo 12 'de, yoğun bakımların şablon kullanım yüzdeleri Şekil 2'de gösterilmiştir. 
International Journal of Scientific and Technological Research ISSN 2422-8702 (Online), DOI: 10.7176/JSTR/6-03-08

Special Issue of Health Sciences, Vol.6, No.3, 2020

Tablo 12. Yoğun Bakımda Kullanılabilecek İstem Şablonları ve Tetkik Grup İçerikleri

\begin{tabular}{|c|c|c|}
\hline $\begin{array}{c}\text { Şablon } \\
\text { Adı }\end{array}$ & $\begin{array}{c}\text { Tetkik } \\
\text { Grupları }\end{array}$ & İçeren Tetkikler \\
\hline \multirow{2}{*}{ Şablon-1 } & \multirow{2}{*}{ Grup-1 } & APTT \\
\hline & & PROTROMBIN ZAMANI \\
\hline \multirow{6}{*}{ Şablon -2 } & \multirow{6}{*}{$\begin{array}{c}\text { Grup } \\
(2,3,4,5)\end{array}$} & ALANIN AMINOTRANSFERAZ \\
\hline & & ASPARTAT TRANSAMINAZ \\
\hline & & FOSFOR \\
\hline & & KAN ÜRE AZOTU \\
\hline & & KREATININ \\
\hline & & MAGNEZYUM \\
\hline \multirow{8}{*}{ Şablon -3 } & \multirow{8}{*}{$\underset{(1,2,3,4,5)}{\text { Grup }}$} & APTT \\
\hline & & PROTROMBİN ZAMANI \\
\hline & & ALANIN AMINOTRANSFERAZ \\
\hline & & ASPARTAT TRANSAMINAZ \\
\hline & & FOSFOR \\
\hline & & KAN ÜRE AZOTU \\
\hline & & KREATININ \\
\hline & & MAGNEZYUM \\
\hline
\end{tabular}




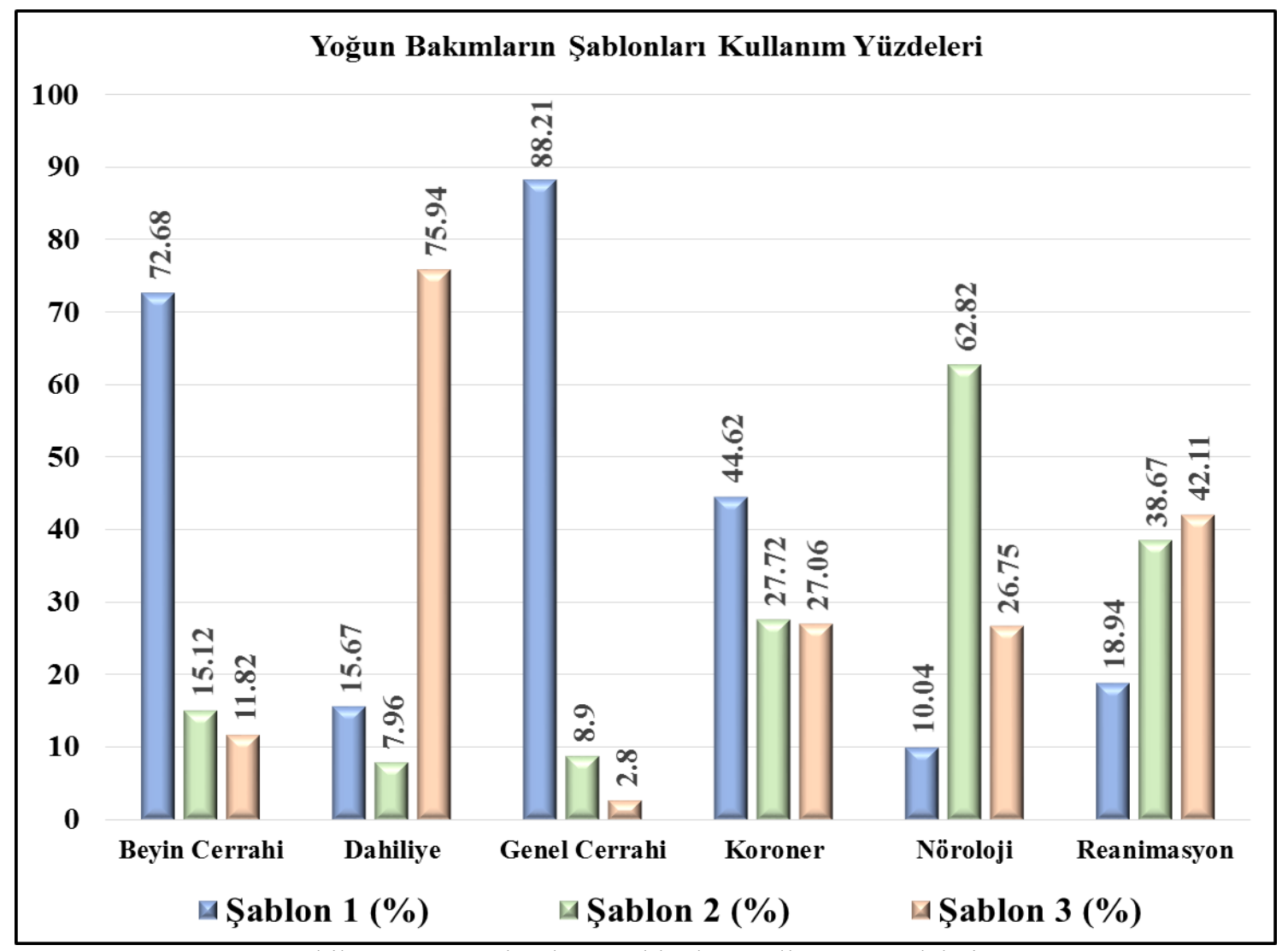

Şekil 2. Yoğun Bakımların Şablonları Kullanım Yüzdeleri

Yoğun bakımlarda şablonların kullanılmasına somut bir örnek olarak Beyin Cerrahi yoğun bakım değerlendirilirse; Şekil-2' görüldüğü gibi, tetkik istemi yapan kişinin önüne ilk gelecek tetkik şablonu Şablon-1 olmalıdır. Zira, Beyin Cerrahi yoğun bakım hastalarının \%72.68'sinde bu tetkikler istenmektedir. Bu şablonun uygun olmadığı hastaya sırasıyla Şablon-2 (\%15.12), Şablon-3 (\%11.82) seçilebilir. Aynı şekilde dahiliye yoğun bakım hastası için ilk şablon Şablon-3 olması zaman tasarrufu sağlayacaktır. Bu şablonun uygun olmadığı durumlardada hekim Şablon-1 (\%15.67), Şablon-2 (\%7.96) seçebilir.

Genel olarak özetlendiğide; Beyin cerrahi ve Genel cerrahi yoğun bakımlarındaki istem şablonları kullanım yüzdeliklerine göre benzerlik göstermektedir. Her iki yoğun bakım istemlerinde daha çok kullanılan Şablon-1, iki birim için de uygun şablon modeli olabilir. Dahiliye yoğun bakımda en çok sıklıkla kullanılan Şablon-3 birime özgü şablon modeli olarak hazırlanabilir. Nöroloji yoğun bakımda Şablon-2'nin yoğunlukla kullanılması birim için uygun model olduğunu gösterir. Koroner yoğun bakımda Şablon-1, Reanimasyonda Şablon-3 modelleri daha büyük yüzdelikle kullanmasının yanı sıra diğer modellerinde belirli bir yüzdelikte kullanılması her iki yoğun bakım içinde Şablon 1, Şablon 2 ve Şablon 3 şablonları içeren model iki birim içinde uygun olabilir.

\section{Sonuç ve Tartışma}

Yoğun bakım hastalarına yapılan tetkikleri içeren istemler ilk aşamada Apriori algoritması ile analiz edilerek birlikte yapılan ilişkili tetkik içeren kayıtlar bulunmuş kayıt sayıları azaltılmış, analiz süresi kısaltılmıştır. Böylelikle, veri setinde birimlerin istem şablonlarını temsil edecek kayıtların belirlenmesi sağlanmıştır. İkinci aşamada; K-ortalama kümeleme sonuçları yoğun bakımlara ait şablonların belirlenmesinde tetkiklerin kullanımları etkili olmuştur. Oluşturulan şablonların yatış süreleri, yaş gibi değişkenlerden çok hastanın tedavi olduğu yoğun bakım birimi ile ilşkili olduğu görülmüştür. HBYS'lerde oluşturacak karar destek sistemleri kapsamında birimlere özgü istem şablonların hazırlanması, hekimlerin istemleri oluşturma aşamalarının daha kolay ve hızlı işlem yapmalarına yardımcı olabilir. Daha önce birim ve hasta profiline göre yapılmış istemler hakkında hekimlerin bilgilendirilmesi laboratuvarda gereksiz istemleri azaltarak, hastalara maliyeti düşük, güvenli ve kaliteli hizmet verilmesine destek sağlayabilir. Sağlık alanında yapılan bu tür çalışmalar sağlık kurumlarının efektif yönetilmesinde önemli bir katma değerdir. 


\section{Kaynaklar}

1. Alexandrova E, Shapekova NL, Ak B, Fügen Özcanaslan F. Health Sciences Research in the Globalizing World. Sofia: ST. Kliment Ohridski University Press. 2018.

2. Global health care Outlook, (2019). www.deloitte.com/healthcare (July 19, 2019).

3. Kelebek Girgin N, İççimen R, Hazıroğlu E, Hacıferat N, Özkaya G, Yılmazlar T, Kutlay. "Yoğun Bakım Hastasında Tanısal Laboratuvar Tetkikleri Nedeniyle Kan Kaybı ve Anemi.” Türk Yoğun Bakım Derneği Dergisi, ( 8):61-65.

4. Cismondi F, Cel, LA, Fialho AS, Vieira SM, Reti SR, Sousa JMC, Finkelstein SN. "Reducing unnecessary lab testing in the ICU with artificial intelligence.” Int J Med Inform 82.5: 345-358.

5. Pala T, Yücedağ İ, Biberoğlu H. "Associattion Rule For Classification Of Breast Cancer Patients." Publications Prepared for the Innovations on Intelligents Systems and Applications Symposium ASYU Sigma J Eng \& Nat Sci 8 .2:155-160.

6. Pazhani Kumar K, Arumugaperumal S. “Association Rule Mining and Medical Application: A Detailed Survey.” International Journal of Computer Applications 80.17: 0975-8887.

7. Sambasiva Rao P, Uma Devi T. “Applicability of Apriori Based Association Rules on Medical Data.” International Journal of Applied Engineering Research ISSN 0973-4562 12.20: 9451-9458.

8. Doddi S, Marathe A, Ravi SS, Torney DC. "Discovery of Association Rules in Medical Data." Medical Informatics and the Internet in Medicine 26(1):25-33.

9. Zhang C, Zhang S. Association Rule Mining_Models and Algorithms. Germany: Springer -Verlag Berlin Heidelberg. 2002.

10. Balaban ME, Kartal E. R ile Veri Madenciliği Uygulamaları. İstanbul: Çağlayan kitap evi Birinci bask1. 2016.

11. Akpınar H. Data Veri Madenciliği Veri Analizi. İstanbul : Papatya Yayıncılık. 2014. 